\title{
Material flow analysis in dissimilar friction stir welding of AA2024 and Ti6Al4V butt joints
}

\author{
Gianluca Buffa ${ }^{1 a}$, Michele De Lisi ${ }^{1}$, Antonio Barcellona ${ }^{1}$ and Livan Fratini ${ }^{1}$ \\ ${ }^{1}$ Department of Chemical, Management, Computer Science and Mechanical Engineering, University of Palermo, Viale delle Scienze, \\ 90128 Palermo, Italy
}

\begin{abstract}
The complex material flow occurring during the weld of dissimilar AA2024 to Ti6A14V butt and lap joints was highlighted through a dedicated numerical model able to take into account the effects of the different materials as well as the phase transformation of the used titanium alloy.
\end{abstract}

Keywords: Friction Stir Welding, titanium alloys, aluminum alloys, FEM

\section{Introduction}

Nowadays aluminum and titanium alloys are extensively used in industrial processes. These alloys offer good mechanical properties and considerable mechanical resistance to weight ratios, which are key parameters in order to improve and optimize the design of vehicles in the aerospace, aeronautical and transportation fields. Moreover, since environment pollution is becoming a significant issue, the reduction of weight, where it is possible through proper materials, is an efficient countermeasure against fuel consumption and, thus, a good strategy to adopt for protecting the environment.

AA2024 is a high-resistant lightweight aluminum alloy, with copper as the primary alloying element, characterized by good atmospheric corrosion resistance and good mechanical properties. It is applied into many fields, typically in aircraft structures, rivets, connectors and miscellaneous structural parts. It is a difficult-to-weld alloy, especially with fusion welding techniques, like ones of AA7xxx series, because of formation and precipitation of hard oxides that brittle the welding and weaken the joining. Porosity can be detected too.

Ti-6Al-4V is an alpha+beta titanium alloy with excellent mechanical properties and corrosion resistance. Due to its phase evolution consisting of three different phases, microstructure and morphology of the alloy are very sensitive to heat treatments changing its mechanical and metallurgical properties. Ti-6Al-4V oxides, whose precipitation is favourite at high temperature, offer strength to the alloy at the expense of its workability.

Traditional fusion welding techniques can be used, but problems as weld cracks, porosities and contaminations appear. FSW is again a suitable solution. Ti-6Al-4V is used mostly in aerospace and aeronautical fields, for building aircraft structures with high added value and compressor blades, but it also used in the biomedical field as main material of prosthesis.

Unfortunately, as known, high-resistant aluminum alloys, such as $2 \mathrm{xxx}$ and $7 \mathrm{xxx}$ ones, and titanium alloys are difficult to weld. In fact, these alloys were considered almost "unweldable" until 1991, when The Welding Institute (TWI) patented the friction stir welding (FSW) process [1]. FSW is a solid-state joining process in which melting temperature is not reached, avoiding the formation of oxides, brittle cast structures, metallurgy porosity and cracking, "hot cracking", large distortion and residual stresses. Because of this, FSW is preferable over traditional fusion welding processes to join aluminum and titanium alloys. After its invention, FSW was applied to several materials and alloys, e.g. aluminum alloys, magnesium alloys, titanium alloys, nickel-copper superalloys, with applications in the aerospace field, shipbuilding and automotive. Researchers and industries have shown interest in studying the process, making it engineered and foretelling eventual defects caused by inappropriate heat input or incorrect plunging settings [2, 3]. Different kinds of geometric set-up were explored changing process parameters such as feed speed, tool rotation rate, tilt angle, plunging depth and relative position between tool and materials and results of various configurations have been scanned. The relevance of tool geometry was investigated and it was found out that it was crucial for the correct material flow and for increasing tensile strength $[4,5]$. In these cases, the tool design influence and pin offsets were analyzed and highlighted too $[6,7]$.

Finally, FSW of dissimilar joints has been studied and demonstrated feasible with the aim to put right materials

\footnotetext{
a Corresponding author: gianluca.buffa@unipa.it
} 
in right places giving more resistance where it is needed and reducing weight where it is possible.

Many studies focused on FSW between different lightweight alloys as magnesium [8] and aluminum ones [9], analyzing different material arrangements and the effects of varying welding parameters on hardness distribution, tensile resistance and joint microstructure. The sheets mutual position, i.e. the position of one sheet in the advancing or in the retreating side, and tool offsets on the tensile strength was investigated for dissimilar joints in which magnesium alloys were welded with aluminum ones [10]. It was obtained that material position deeply influences the final microstructure of the weld and its mechanical and metallurgical properties. The right positioning is determinant in order to avoid inappropriate heat inputs and, hence, unwanted liquid formation and intermetallic compounds [11]. Additionally, choosing the most suitable offset is fundamental for obtaining higher tensile strength. Studies were conducted about the relevance of the cooling conditions in dissimilar $\mathrm{Mg}-\mathrm{Al}$ joints and the different effects of underwater cooling rather than air cooling on hardness (which resulted lower in the first case), tensile strength (which decreased in the second case) and formation of intermetallic compounds (which was reduced in the first case) [12].

A few researches focused on the applicability of friction stir welding to titanium alloys and on its characterization $[13,14]$, trying to find out engineered process parameters. Mostly because of their thermal properties, it was deduced that low tool rotation rates and low feed rates are eligible for titanium alloys [15]. Hence, it was widely demonstrated the feasibility of FSW for Ti6Al4V, which is largely used overall in aerospace field. In addition to this, friction stir welded joints with super alloys have been realized with successful results [16].

Only a very limited number of papers is found on the FSW of dissimilar aluminum to titanium joints. Li et al. [17] studied the influence of process variables on the weld interfaces and tensile properties of Ti-6Al-4V alloy to Al$6 \mathrm{Mg}$ alloy. It was found that higher joint mechanical tensile strength can be reached wen the Ti-Al diffusion bonding interlayer is obtained. Wu et al. [18] examined the influence of welding parameters on the interface and the properties of a Ti-6Al-4V alloy to AA6061 alloy joint investigating the macrostructure of the joint, the fracture surfaces and the reaction layer. Continuous $\mathrm{TiAl}_{3}$ intermetallic compounds at the interface of the two materials were found with the welding parameters used. The interface thickness, key factor for obtaining good tensile strength and appropriate fracture locations, resulted associated to the rotating rate. The joints bonded at the rotating rate of $750 \mathrm{rpm}$ failed in the TMAZ/HAZ and had the highest tensile strength, accompanied with the perfect bonded and thin interface. However, the complex material flow occurring the two largely different materials is still unclear. A properly designed numerical model of the process can help in the understanding of the occurring process mechanics enabling the use of these joints for industrial applications.

In the last years, different research groups have been working on the development of a dedicated numerical model for FSW. Thermo-mechanically coupled FEM models have been developed [19, 20]. Good agreement and fine matching have been achieved between numerical and experimental results in terms of predicting the effect of process parameters on process thermo-mechanics and temperature distribution. Similar and dissimilar joints have been analyzed with finite element methods, in order to understand material flow, strain, strain rate and temperature distributions, verified by experimental validation [21, 22]. FEM modelling have been successfully adopted also for investigating the feasibility of the friction stir welding of tailor-welded blanks [23], finding that joint morphology, heat input and forces are strictly dependent from the increase of the thickness ratio. However, FEA of FSW is still not enough mature in terms of analyzing and predicting material flow, temperature distribution and effects of geometrical and material arrangements of dissimilar butt and lap joints of the most used alloys such as aluminum, magnesium and titanium ones. As far as the authors know, there are no papers on the FEM models of FSW between Ti-6Al-4V and an aluminum high-resistant alloy highlighting the occurring material flow.

In this paper, a dedicated numerical model capable to take into account the complex material flow occurring in dissimilar FSW of titanium and aluminum alloys, in different configurations, was developed. The model is able to predict material flow, temperature, strain and strain rate distributions.

\section{Numerical model set up}

A Lagrangian, thermo-mechanically coupled 3D FEM model with a rigid visco-plastic material model was developed. The analysis was conducted using the 3D version of the implicit lagrangian code DEFORM ${ }^{\mathrm{TM}}$. The implemented FEM formulation is based on the variational approach where the actual velocity (the solution) among all admissible velocities that satisfy the compatibility conditions, incompressibility and the boundary condition cause a functional to assume a stationary value. Workpiece and tool geometries were imported into DEFORM ${ }^{\mathrm{TM}}$ from a commercial CAD software. FSW of AA2024 and Ti$6 \mathrm{Al}-4 \mathrm{~V}$ dissimilar joint, $1.6 \mathrm{~mm}$ in thickness, in butt configuration was modeled. Temperature, strain, and strain rate material flow were considered for the two materials. AA2024 material data were taken from the material library of the software, Ti-6Al-4V material data were taken from previous studies [24, 25]. Fig. 1 shows the utilized curves, as a function of temperature. It is worth noticing material flow stress was input in the model in the form of tabular data.

Tool and workpiece were meshed with tetrahedral elements. The workpiece model consisted of about 45,000 elements, whereas the tool, characterized by shoulder of $13 \mathrm{~mm}$, conical pin with base diameter of $5 \mathrm{~mm}$ and tip diameter of $3.5 \mathrm{~mm}$, was modelled as a rigid object (in tungsten carbide) and meshed with about 10,000 elements for the thermal analysis only. Both butt and lap configurations were analyzed. Tool was tilted of $2^{\circ}$ for all the simulations. In order to simulate a dissimilar friction stir welded joint, a fictitious phase transformation had to be set. In fact, the workpiece is formed by a single material object in both simulations. The material model of the 
workpiece was set as a bi-phasic material in which the two phases are Ti-6Al-4V and AA2024. The single-block workpiece was made of one of the two phases, i.e. AA2024. Then a fictitious transformation is induced in such a way that the part corresponding to the titanium sheet changes its phase into titanium one. After it was completed, this transformation was disabled, obtaining a starting workpiece composed of the two alloys considered. A similar approach was used by some of the authors to simulate dissimilar FSW of Ti-6Al-4V and AISI 304 [21]. Further details on the numerical approach used for the phase change can be found in the above mentioned paper.
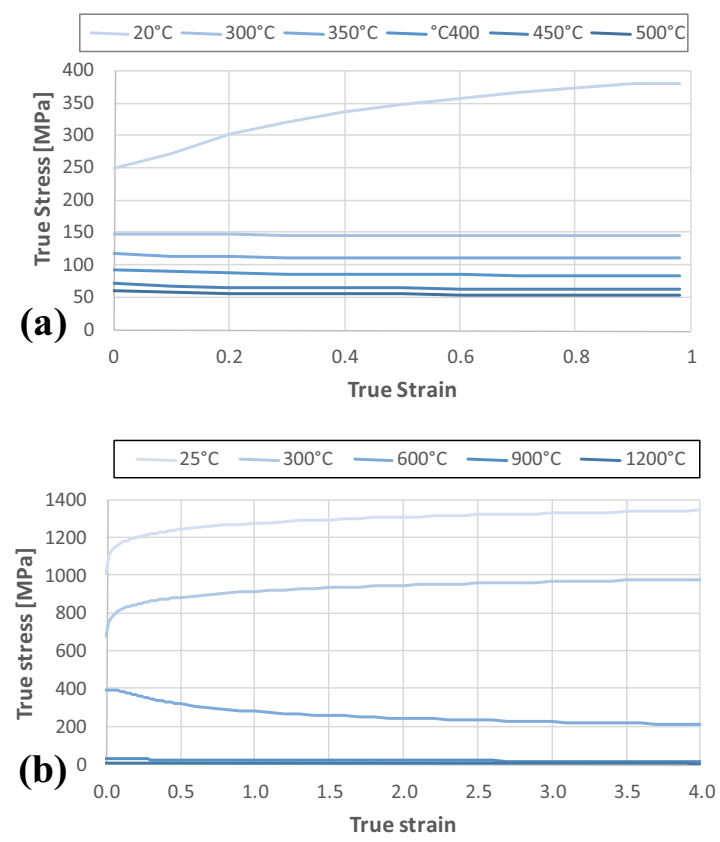

Figure 1. flow stress curves for fixed strain rate of $0.3 / \mathrm{s}$ for (a) AA2024 and (b)Ti6A14V

Furthermore, pressurized argon impinging jet shielding has been implemented with a toroidal environment window. The heat exchange coefficient used was $1.9 \mathrm{~N} \cdot \mathrm{s}^{-}$ ${ }^{1} \cdot \mathrm{mm}^{-1} \cdot{ }^{\circ} \mathrm{C}^{-1}$. Heat transfer with the environment at the room temperature of $20^{\circ} \mathrm{C}$ was enabled. The heat exchange coefficient used was $0.02 \mathrm{~N} \cdot \mathrm{s}^{-1} \cdot \mathrm{mm}^{-1} \cdot{ }^{\circ} \mathrm{C}^{-1}$.

The initial configuration of the butt joint model is displayed in Fig. 2 indicating also materials position.

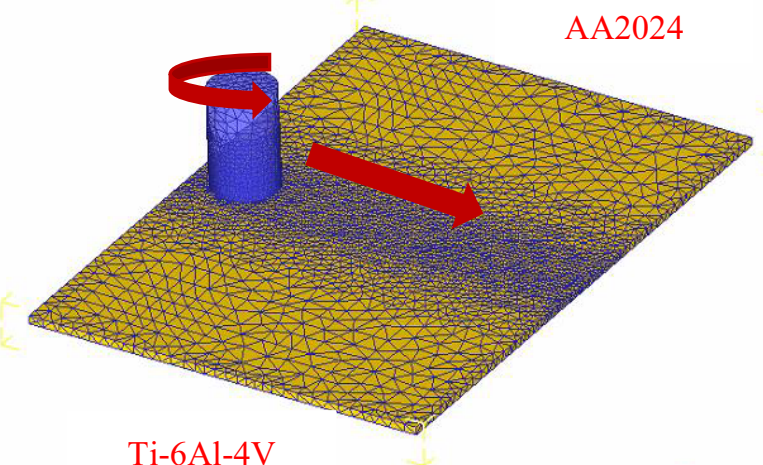

Ti-6Al-4V

Figure 2. Starting meshed model of the butt joint
On the left side of the tool, which is the retreating one, AA2024 was placed. Ti-6Al-4V was in the advancing side (AS). This choice was due based results of previous studies demonstrating that the harder material must be placed in the AS in order to maximize joint performances $[11,17$, 18]. Tool rotation rate was adjusted at $900 \mathrm{rpm}$ and feed rate at $3.33 \mathrm{~mm} / \mathrm{s}$. Finer mesh windows were implemented in order to have a better resolution of the results along the weld seam. In addition to this, an adaptive remesh was enabled and deformation and step triggers were considered. A large number of remeshing step occurs during the process due to the large deformation induced by the tool action. The automatic remeshing algorithm of the utilized softhearted was used and remeshing was triggered by assigning maximum element distortion of $50 \%$.

Regarding inter-objects relations, the shear model, according to which the shear stress is equal to a certain percentage of the material shear flow stress, was utilized. In particular, a constant factor of 0.45 was used to model the contact between the tool and the aluminum alloy sheet, whereas a constant factor of 0.35 was applied at the contact between the titanium alloy and the tool. These values are taken from previous studies of the authors on similar welds for the considered materials [19-25]. Furthermore, a constant interface heat exchange coefficient of $11 \mathrm{~N} \cdot \mathrm{s}$ ${ }^{1} \cdot \mathrm{mm}^{-1} \cdot{ }^{\circ} \mathrm{C}^{-1}$ was used for the parts of the workpiece that were in contact with the tool. As the CPU time ids considered, only a few minutes were needed in order to simulate the phase change while the welding process, including the tool plunge and the tool movement along the weld seam, took about 20 hours. Two different configurations have been examined. First, zero tool offset was considered, i.e. the tool axis corresponds to the separation line between the two materials. Then, an offset equal to $1.75 \mathrm{~mm}$ was given to the tool shifting it towards the aluminum side. Fig. 3 shows a sketch of the considered configurations. The position of the two different materials with respect to the advancing and retreating side of the joint is also highlighted.

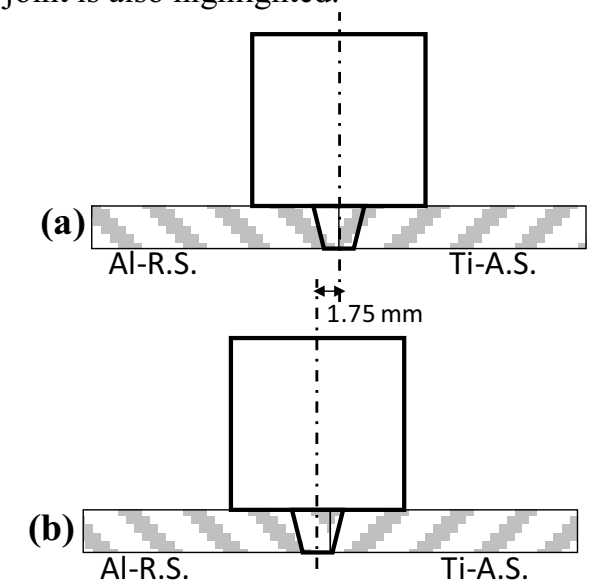

Figure 3. Sketch of the considered configurations: (a) zero-offset and (b) offset

The different material flow and main field variables distributions were used to highlight the changes in the process mechanics due to the offset. 


\section{Results}

First, temperature dsitributions have been studied. Fig.4 shows the temperature distribution in a top view of the joint for the two configurations. The initial separation line between the two materials is highlighted. A few considerations can be made on the figure. As expected, larger temperatures are found in the titanium side, with peak values of about $990^{\circ} \mathrm{C}$. However, although similar peak values are found for both configurations, the extension of the area involved by large temperature is smaller when an offset is given to the tool. This is due to the reduced contact surface between the tool and the titanium sheet. In particular, in the zero-offset configuration the red area, corresponding to the highest temperatures, is found also in the side of the joint where aluminum should be present. This would result in local melting of the AA2024 alloy, with detrimental effects on the joint nugget integrity. Nevertheless, as it will be better explained in the following paragraph, titanium is ofund also in the RS of the joint due to the occurring material flow. Additionally, it arises that large temperatures are found close to the tool pin also for the offset configuration (orange areas). Finally, larger areas characterized by temperature higher that room temperature, are found in the aluminum side due to the larger thermal conductivity of this alloy with respect to the titanium alloy.

(a)
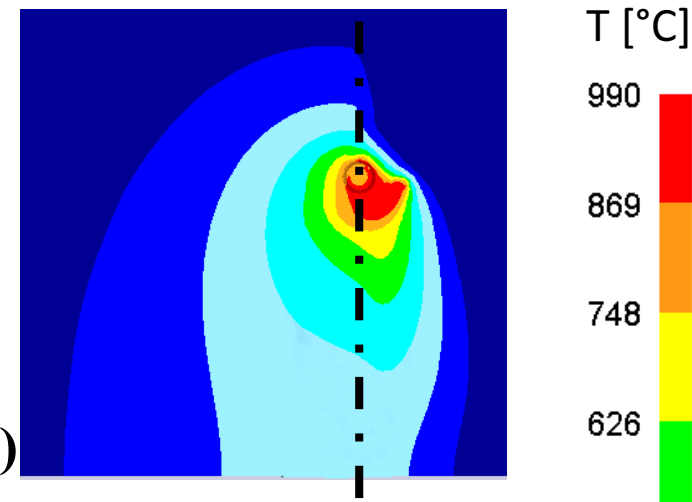

(b)

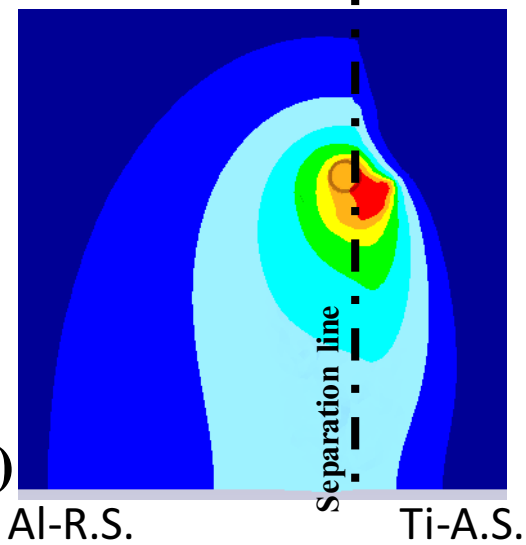

626

505

384

263

141

20.0

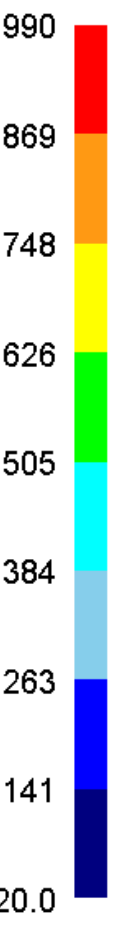

Figure 4. Temperature distribution in a top view of the joints: (a) zero-offset and (b) offset configuration

Temperature profiles in a cross section of the joint have been calculated. It is worth noticing that the cross section was taken after the tool advanced $40 \mathrm{~mm}$ in order to be sure that the process reached the steady state. Fig.5 shows the obtained curves as well as a sketch of the abscissa used for data extraction, which was at mid height of the cross section, i.e. $0.8 \mathrm{~mm}$ from the top surface of the joint. The analysis of the curves confirms that similar maximum temperature is reached in the titanium side, while larger temperature is reached in the aluminum side when the zero-offset configuration is used. Additionally, temperature below $600^{\circ} \mathrm{C}$ are reached, in the aluminum side, at a distance from the initial separation line of about $4.5 \mathrm{~mm}$ and $5.5 \mathrm{~mm}$ for the zero-offset and offset configurations, respectively.

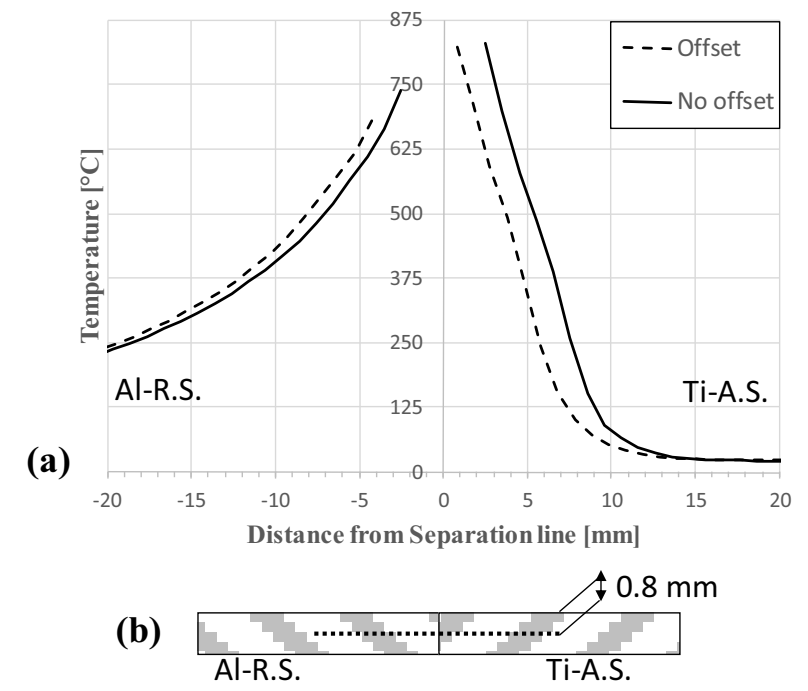

Figure 5. (a) temperature profiles in a cross section for the two configurations and (b) sketch of the cross section highlighting the position of the abscissa used for data extraction.

In order to explain this behavior and assess whether local melting occurs, the material flow was investigated. Fig. 6 shows the strain distribution in a cross section, taken after $40 \mathrm{~mm}$ of weld length, for the two considered case studies. The position of the tool and the initial separation line between the two sheets are highlighted.

(a)

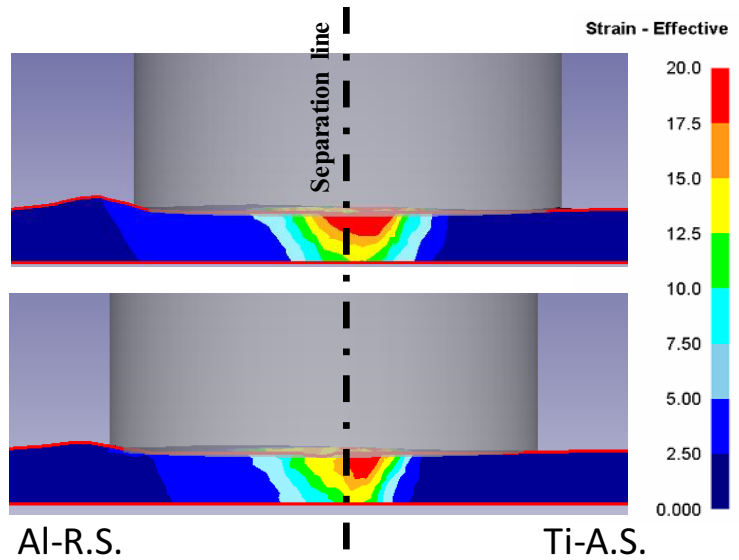

Figure 6. Strain distribution in a cross section of the joint for the (a) zero-offset and (b) offset configurations.

Similarly to what observed for the temperature, maximum values, consistent with what found in literature [21], are found in the titanium side. Again, the area involved by the highest values of accumulated strain is larger for the zero-offset case study, affecting part of the retreating side of the joint, i.e. where aluminum was initially placed. In a similar way, also the area of the 
retreating side affected by significant accumulated strain values, i.e. in excess of 2.5 , is larger for the zero-offset case study.

As described in the previous paragraph, the presence of the two different materials in the "single block" model was taken into account by creating a new biphasic material in which the two phases correspond to the AA2024 and Ti6Al4V. Hence, the position of the two materials can be analyzed by calculating the volume fraction of one of the two phases. Fig. 7 shows the distribution of the volume fraction of the AA2024 in a top view of the joint, while Fig. 8 shows the nodal velocity vectors during the process, for both the configurations. (a)

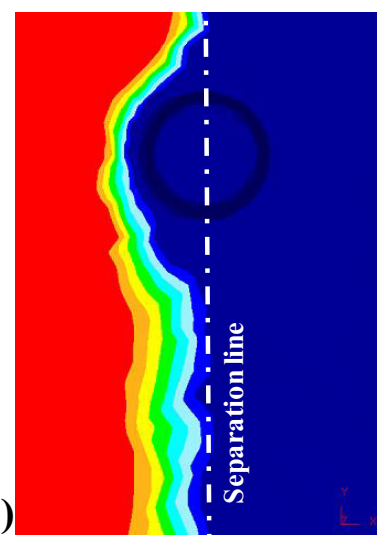

Volume fraction - AA2024

$$
\text { Al-R.S. }
$$

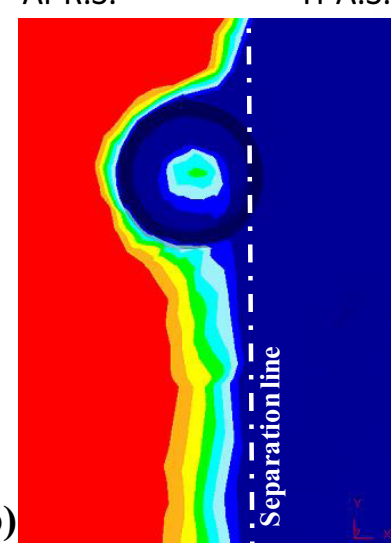

Al-R.S.

Ti-A.S.
1.00
0.875
0.750
0.625
0.500
0.375
0.250
0.125
0.000
Figure 7. AA2024 volume fraction during the weld for the (a) zero-offset and (b) offset case studies

A significantly different material flow is observed. As the zero-offset case study is taken into account, it can be observed that in the retreating side, i.e. where aluminum was initially placed, titanium is found. The material flow can be described as follows: titanium rotates together with the tool from the advancing side to the retreating side pushing away from the tool axis, the aluminum. Then, titanium closes right back the tool pin and final bond with aluminum, represented by the area in which the two materials are mixed and AA2024 volume fraction is between 0.25 and 0.875 , is obtained in the advancing side "far" from the tool pin, i.e. at a distance of about $4 \mathrm{~mm}$ in the trailing edge of the joint. On the other hand, when an offset is given to the tool, AA2024 is not pushed towards the periphery of the retreating side but bonds with the titanium coming from the advancing side in front of the tool. This is visible observing the red area in front of the tool pin also in the advancing side. Then, the two materials rotate with the tool and are left right behind it forming a mixed materials band centered with the tool axis. The lack of material mixing and material flow observed for the zerooffset configuration behind the tool in the retreating side, is highlighted by the light grey area in Fig.8a, as compared to the same area shown Fig. 8b for the offset configuration. The combination of larger velocity and material rotation close to the tool pin indicates that proper conditions for solid bonding are achieved for the offset case study.

(a)

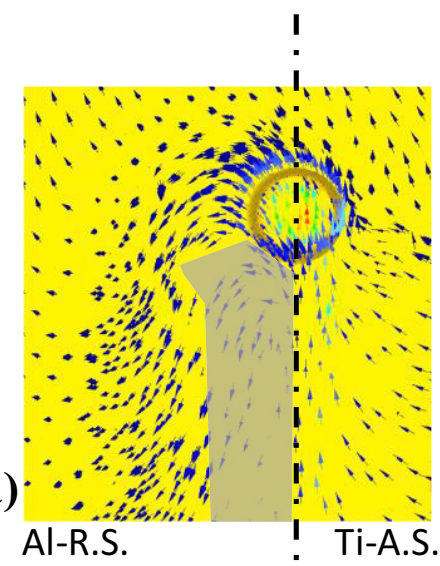

(b)

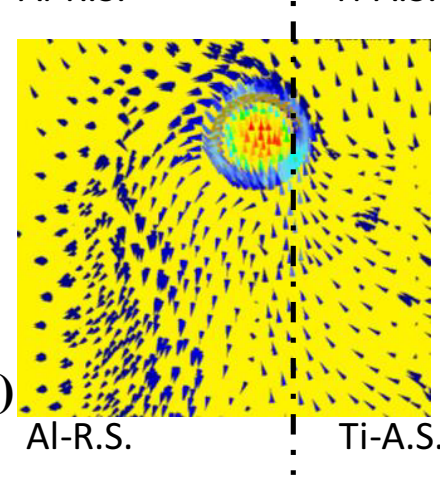

Figure 8. Nodal velocity vectors during the weld for the (a) zerooffset and (b) offset case studies

Finally, it should be observed that, for the offset case study, due to the occurring process mechanics, "pure" AA2024 is found at a distance of about $6 \mathrm{~mm}$ from the separation line. This value is the sum of the pin major diameter and the mixed material band rotating with the tool in the cross section containing the pin. In this way, it can be stated that local melting, detrimental to the joint integrity because of the deformation of brittle intermetallics, does not take place in this process conditions.

\section{Conclusions}

A numerical analysis on the process mechanics in FSW of dissimilar AA2024 and Ti6A14V butt joints is presented.

From the obtained results it can be concluded that, both the zero-offset and the offset condition result in proper local values of temperature and accumulated strain in order to obtain sound welds. However, shifting the tool towards the low melting material results in a more effective 
material flow behind the tool and better materials mixing highlighted by a mixed materials band formed close to the tool.

\section{References}

1. W.M. Thomas, E.D. Nicholas, J.C. Needham, M.G. Murch, P. Temple Smith, C.J. Dawes, G.B. Patent Application No. 9125978.8, (1991)

2. R. Nandan, T. DebRoy, H.K.D.H. Bhadeshia, Prog Mater Sci, Recent advances in friction-stir welding Process, weldment structure and properties, 53 (6), pp. 980-1023, (2008), doi:10.1016/j.pmatsci.2008.05.001

3. Y.G. Kima, H. Fujii, T. Tsumura, T. Komazaki, K. Nakata, Mat Sci Eng A-Struct, Three defect types in friction stir welding of aluminum die casting alloy, 415 (1-2), pp. 250-254, (2006), doi:10.1016/j.msea.2005.09.072

4. R.S. Mishra, Z.Y. Mab, Mat Sci Eng R, Friction stir welding and processing, 50 (1-2), pp. 1-78, (2005), doi:10.1016/j.mser.2005.07.001

5. S. Tiwari, H. Chelladurai, A. K. Shukla, 5th International \& 26th All India Manufacturing Technology, Design and Research Conference (AIMTDR 2014), Parametric Analysis of Friction Stir Welding, (IIT Guwahati, Assam, India, December $12^{\text {th }}$ $14^{\text {th }}$ 2014), http://www.iitg.ernet.in/aimtdr2014/PROCEEDINGS/ papers/528.pdf

6. K. P. Mehta, V. J. Badheka, Int J Adv Manuf Tech, Influence of tool design and process parameters on dissimilar friction stir welding of copper to AA6061T651 joints, 80 (9), pp. 2073-2082, (2015), doi:10.1007/s00170-015-7176-1

7. M. Aonumaa, K. Nakata, Mat Sci Eng B-Solid, Dissimilar metal joining of ZK60 magnesium alloy and titanium by friction stir welding, 177 (7), pp. 543-54, (2012), doi:10.1016/j.mseb.2011.12.031

8. D. Liu, R. Xin, X. Zheng, Z. Zhou, Q. Liu, Mat Sci Eng A-Struct, Microstructure and mechanical properties of friction stir welded dissimilar Mg alloys of ZK60AZ31, 561, pp. 419-426, (2013), doi:10.1016/i.msea.2012.10.052

9. S. A. Khodir, T. Shibayanagi, Mat Sci Eng B-Solid, Friction stir welding of dissimilar AA2024 and AA7075 aluminum alloys, 148 (1-3), pp. 82-87, (2008), doi:10.1016/j.mseb.2007.09.024

10. G. Buffa, D. Baffari, A. Di Caro, L. Fratini, Sci Technol Weld Joi, Friction stir welding of dissimilar aluminum-magnesium joints: sheet mutual position effects, 20 (4), pp. 271-279, (2015), doi:10.1179/1362171815Y.0000000016

11. V. Firouzdor, S. Kou, Metall Mater Trans A, Al-to-Mg Friction Stir Welding: Effect of Material Position, Travel Speed, and Rotation Speed, 41 (11), pp. 29142935, (2010), doi:10.1007/s11661-010-0340-1

12. Y. Zhao, S. Jiang, S. Yang, Z. Lu1, K. Yan, Int J Adv Manuf Tech, Influence of cooling conditions on joint properties and microstructures of aluminum and magnesium dissimilar alloys by friction stir welding, pp. 1-7, (2015), doi:10.1007/s00170-015-7624-y

13. M. Ramulu, P.D. Edwards, D.G. Sanders, A.P. Reynolds, T. Trapp, Mater Design, Tensile properties of friction stir welded and friction stir weldedsuperplastically formed Ti-6Al-4V butt joints, 31 (6), pp. 3056-3061,

(2010),

doi:10.1016/j.matdes.2010.01.023

14. S, Nimera, J. Wolkb, M. Zupan, Acta Mater, Local property characterization of friction stir welded $T i$ 5111: Transverse orientation measurements, 61 (8), pp. 3050-3059,

(2013),

doi:10.1016/j.actamat.2013.01.065

15. L. Zhou, H.J. Liu, Q.W. Liu, Mater Design, Effect of rotation speed on microstructure and mechanical properties of Ti-6Al-4V friction stir welded joints, 31 (5), pp. 2631-2636, (2010), doi:10.1016/j.matdes.2009.12.014

16. M. M. Z. Ahmed, B. P. Wynne, J. P. Martin, Sci Technol Weld Joi, Effect of friction stir welding speed on mechanical properties and microstructure of nickel based super alloy Inconel 718, 18 (8), pp. 680-687, (2013), doi: 10.1179/1362171813Y.0000000156

17. B. Li, Z. Zhang, Y. Shen, W. Hub, L. Luo, Mater Design, Dissimilar friction stir welding of Ti-6Al-4V alloy and aluminum alloy employing a modified butt joint configuration: Influences of process variables on the weld interfaces and tensile properties, 53, pp. 838848, (2014), doi:10.1016/j.matdes.2013.07.019

18. A. Wua, Z. Song, K. Nakata, J. Liao, L. Zhou, Mater Design, Interface and properties of the friction stir welded joints of titanium alloy Ti6Al4V with aluminum alloy 6061, 71, pp. 85-92, (2015), doi:10.1016/j.matdes.2014.12.015

19. G. Buffa, J. Hua, R. Shivpuri, L. Fratini, Mat Sci Eng A-Struct, A continuum based fem model for friction stir welding-model development, 419 (1-2), pp. 389-396, (2006), doi:10.1016/j.msea.2005.09.040

20. K. Gök, M. Aydin, Int J Adv Manuf Tech, Investigations of friction stir welding process using finite element method, 68, pp. 775-780, (2013), doi:10.1007/s00170-013-4798-Z

21. G. Buffa, Int J Mater Form, Joining Ti6Al4V and AISI 304 through friction stir welding of lap joints: experimental and numerical analysis, 9 (1), pp. 59-70, (2014), doi:10.1007/s12289-014-1206-7

22. M. Abbasi, B. Bagheri, R. Keivani, J Mech Sci Tech, Thermal analysis of friction stir welding process and investigation into affective parameters using simulation, 29 (2), pp. 861-866, (2015), doi:10.1007/s12206-015-0149-3

23. G. Buffa, L. Fratini, R. Shivpuri, Comput Struct, Finite element studies on friction stir welding processes of tailored blanks, 86 (1-2), pp. 181-189, (2008), doi:10.1016/i.compstruc.2007.04.007 
24. G. Buffa, A. Ducato, L. Fratini, Mat Sci Eng A-Struct, FEM based prediction of phase transformations during Friction Stir Welding of Ti6Al4V titanium alloy, 581, pp. 56-65, (2013), doi:10.1016/j.msea.2013.06.009

25. G. Buffa, A. Ducato, L. Fratini, AIP Conference Proceedings, Dissimilar material lap joints by friction stir welding of steel and titanium sheets: Process modelling, 1532, pp. 491-498, (2013), doi:10.1063/1.4806866 